P. M. J. McSheehy · R. E. Port · L. M. Rodrigues

S. P. Robinson - M. Stubbs

K. van der Borns · G. J. Peters

I. R. Judson · M. O. Leach · J. R. Griffiths

\title{
Investigations in vivo of the effects of carbogen breathing on 5-fluorouracil pharmacokinetics and physiology of solid rodent tumours
}

Received: 7 February 2004/ Accepted: 26 April 2004/Published online: 5 October 2004

(C) Springer-Verlag 2004

\begin{abstract}
Purpose: We have shown previously that carbogen $\left(95 \% \mathrm{O}_{2}, 5 \% \mathrm{CO}_{2}\right)$ breathing by rodents can increase uptake of anticancer drugs into tumours. The aim of this study was to extend these observations to other rodent models using the anticancer drug 5-fluorouracil $(5 \mathrm{FU}) .5 \mathrm{FU}$ pharmacokinetics in tumour and plasma and physiological effects on the tumour by carbogen were investigated to determine the locus of carbogen action on augmenting tumour uptake of $5 \mathrm{FU}$. Methods: Two different tumour models were used, rat GH3 prolactinomas xenografted s.c. into nude mice and rat H9618a hepatomas grown s.c. in syngeneic Buffalo rats. Uptake and metabolism of $5 \mathrm{FU}$ in both tumour
\end{abstract}

P. M. J. McSheehy · L. M. Rodrigues · S. P. Robinson

M. Stubbs · J. R. Griffiths

Department of Biochemistry, Cancer Research UK Biomedical Magnetic Resonance Research Group, St George's Hospital Medical School, Cranmer Terrace, London, SW17 0RE, UK

P. M. J. McSheehy · M. O. Leach

Cancer Research UK Clinical Magnetic Resonance Research Group, Institute of Cancer Research and Royal Marsden NHS

Trust, Sutton, Surrey, SM2 5PT, UK

P. M. J. McSheehy · I. R. Judson

Cancer Research UK Centre for Cancer Therapeutics,

Institute of Cancer Research, Sutton, Surrey, SM2 5NG, UK

P. M. J. McSheehy $(\bowtie)$

Oncology Research, WKL 125.2.05,

Novartis Institutes for BioMedical Research,

Basel, 4002, Switzerland

E-mail: paul_mj.mcsheehy@pharma.novartis.com

Tel.: + 41-61-6968189

Fax: + 41-61-6965751

R. E. Port

Unit Pharmacology and Anticancer treatment,

German Cancer Research Centre, Heidelberg, Germany

K. van der Borns · G. J. Peters

Department Medical Oncology, VU University Medical Centre,

De Boelelaan 1117, 1081 HV Amsterdam, The Netherlands models with or without host carbogen breathing was studied non-invasively using fluorine-19 magnetic resonance spectroscopy $\left({ }^{19} \mathrm{~F}\right.$-MRS), while plasma samples from Buffalo rats were used to construct a NONMEM pharmacokinetic model. Physiological effects of carbogen on tumours were studied using ${ }^{31} \mathrm{P}$-MRS for energy status $(\mathrm{NTP} / \mathrm{Pi})$ and $\mathrm{pH}$, and gradient-recalled echo magnetic resonance imaging (GRE-MRI) for blood flow and oxygenation. Results: In both tumour models, carbogan-induced GRE-MRI signal intensity increases of $\sim 60 \%$ consistent with an increase in tumour blood oxygenation and/or flow. In GH3 xenografts, ${ }^{19} \mathrm{~F}$-MRS showed that carbogen had no significant effect on $5 \mathrm{FU}$ uptake and metabolism by the tumours, and ${ }^{31} \mathrm{P}-\mathrm{MRS}$ showed there was no change in the $\mathrm{NTP} / \mathrm{Pi}$ ratio. In H9618a hepatomas, ${ }^{19}$ F-MRS showed that carbogen had no effect on tumour 5FU uptake but significantly $(p=0.0003)$ increased 5FU elimination from the tumour (i.e. decreased the $\left.t_{1 / 2}\right)$ and significantly $(p=0.029)$ increased $(53 \%)$ the rate of metabolism to cytotoxic fluoronucleotides (FNuct). The pharmacokinetic analysis showed that carbogen increased the rate of tumour uptake of 5FU from the plasma but also increased the rate of removal. ${ }^{31} \mathrm{P}-\mathrm{MRS}$ showed there were significant $(p \leq 0.02)$ increases in the hepatoma NTP/Pi ratio of $49 \%$ and transmembrane $\mathrm{pH}$ gradient of 0.11 units. Conclusions: We suggest that carbogen can transiently increase tumour blood flow, but this effect alone may not increase uptake of anticancer drugs without a secondary mechanism operating. In the case of the hepatoma, the increase in tumour energy status and $\mathrm{pH}$ gradient may be sufficient to augment 5FU metabolism to cytotoxic FNuct, while in the GH3 xenografts this was not the case. Thus carbogen breathing does not universally lead to increased uptake of anticancer drugs.

Keywords 5-Fluorouracil - Tumour · Carbogen · Pharmacokinetics $\cdot$ MRS $\cdot$ MRI 
Abbreviations AUC: Area under the concentration-time curve $\cdot C_{\text {max }}$ : Maximum value $\cdot$ DHFU: Dihydrofluorouracil - 5FU: 5-Fluorouracil - FTP: 5Fluorotryptophan - FBal: 5-Fluoro- $\beta$-alanine $\cdot$ FUPA: 5-Fluoro- $\beta$-ureidopropionic acid - FNuct: 5-Fluoronucleotides - FCat: Fluorocatabolites - GRE: Gradient recalled-echo - MRS: Magnetic resonance spectroscopy $\cdot \mathrm{NaF}$ : Sodium fluoride $\cdot \Delta \mathrm{pH}: \mathrm{pH}$ gradient across the plasma membrane $\cdot t_{1 / 2}: 5 \mathrm{FU}$ elimination half-life $\cdot V_{1}: 5 \mathrm{FU}$ in the body $\cdot V_{2}: 5 \mathrm{FU}$ in the tumour $\mathrm{CL}_{10}$ : $5 \mathrm{FU}$ elimination from the body $\mathrm{CL}_{\mathrm{d}}$ : Bi-directional clearance of $5 \mathrm{FU}$ (body and tumour) $\cdot \mathrm{CL}_{\mathrm{m}}$ : Metabolic clearance of $5 \mathrm{FU}$ in the tumour

\section{Introduction}

A major factor in the relatively low success of systemic anticancer chemotherapy is inadequate drug delivery to the solid tumour. This is partly due to the poor vascular supply of solid tumours which additionally leads to hypoxic regions, as well as the high hydrostatic pressure in the tumour extracellular space [5]. There is thus a clinical need to improve drug delivery for both new and old chemotherapeutics for the treatment of the majority of solid tumours.

Breathing carbogen $\left(95 \% \mathrm{O}_{2}, 5 \% \mathrm{CO}_{2}\right)$ by rats and mice has been shown to increase the uptake of anticancer drugs by solid tumours $[13,19,31,32]$. In the GH3 prolactinoma grown in syngeneic rats, carbogen increased the maximum concentration of ifosfamide $\left(C_{\max }\right)$ in the tumour by $60 \%$ and although time for drug elimination $\left(t_{1 / 2}\right)$ was unchanged, the area under the concentration-time curve (AUC) was significantly increased. Uptake and retention of ifosfamide by the liver [31] and other normal tissues were unchanged [29] showing that the effect of carbogen was selective for tumours. In mouse RIF-1 fibrosarcomas grown in syngeneic mice, carbogen decreased the rate of elimination of 5 -fluorouracil (5FU) by $30 \%$, and caused increased 5FU uptake and activation, although the latter effect only occurred in tumours which were considered hypoxic due to high retention of a nitroimadazole [19]. In both these animal tumour models, carbogen augmented drug-induced growth inhibition of the tumour. The mechanism of these effects is complex, but a major factor is likely to be a carbogeninduced transient increase in blood flow and/or blood volume to all or part of the tumour. However, other changes in rodent tumours also occur in response to carbogen breathing which include decreases in extracellular $\mathrm{pH}[19,37]$ and increases in tissue oxygenation $[1,8,30]$, and they may also play a role in the increased retention of $5 \mathrm{FU}$ by tumours. $5 \mathrm{FU}$ is a pro-drug which is metabolised in tissues to 5-fluoronucleotides (FNuct), or degraded (mostly in the liver) to non-cytotoxic catabolites such as fluoro- $\beta$-alanine. Increased tumour concentrations of $5 \mathrm{FU}$ are strongly associated with improved response both in pre-clinical and clinical models $[17-19,24,26,35]$. Thus, a mechanism that leads to increased uptake and/or retention of $5 \mathrm{FU}$ by tumours will lead to increased tumour cell kill.

Gradient-recalled echo (GRE) imaging of GH3 tumours grown in rats showed that carbogen caused a rapid and completely reversible twofold increase in image intensity [27], a phenomenon that reflects predominantly an increase in tumour blood oxygenation, as well as heterogeneous increases in tumour blood flow $[10,30]$. Investigation of five other solid tumour models grown in rodents showed that carbogen induced similar or smaller increases in three of these models, namely, the same GH3 tumour xenografted into nude mice, the Morris hepatoma, H9618a transplanted into syngeneic rats and a chemically induced rat mammary adenocarcinoma. However, in the two other models, the RIF-1 fibrosarcoma grown in syngeneic mice and the human HT29 adenocarcinoma xenografted in nude mice, transient decreases in image intensity were observed [28]. In human tumour studies, the responses to carbogen were also variable. Over $70 \%$ of the tumours studied showed an increase in signal intensity, with a range of increases from $4 \%$ to $80 \%$ [7, 38]. A recent report measured the effect of carbogen on the oxygenation of RIF-1 tumours and demonstrated considerable variability in the changes in $\mathrm{pO}_{2}$ ranging from no effect $(4 / 10)$ to increases of $20-50 \% \quad(4 / 10)$ to $>8$-fold increases $(2 / 10)$ [12]. Taken together, all these experiments suggest that the effect of carbogen breathing on anticancer drug uptake by tumours could also be very variable too.

In order to investigate further the influence of carbogen on 5FU pharmacokinetics and tumour physiology, we have measured changes in tumour $5 \mathrm{FU}$ uptake and metabolism and GRE-image intensity in response to carbogen in the Morris rat hepatoma H9618a and in the GH3 prolactinoma xenografted into nude mice. The H9618a hepatoma was selected because we have shown there is a large physiological response to carbogen: the ATP/Pi ratio and $\mathrm{pO}_{2}$ both increase [37], and in the GH3 tumour we had already shown that carbogen could increase the initial uptake of the anticancer drug ifosfamide [31]. In the rat hepatoma, 5FU uptake and metabolism in the tumour was modelled pharmacokinetically to determine the locus of carbogen action. The results show that carbogen can rapidly increase drug uptake from the plasma, but simultaneously increases drug elimination from the tumour tissue space back to plasma. Thus, for carbogen to increase tumour uptake of $5 \mathrm{FU}$, a secondary mechanism may be necessary, involving for example a decrease in tumour $\mathrm{pH}$. Such a change was observed in hypoxic RIF-1 tumours [19] and this or other changes may be required in order to obtain therapeutic benefit from carbogen breathing. 


\section{Methods}

Materials 5FU was obtained from David Bull Laboratories (Warwick, UK) as a saline solution of $25 \mathrm{mg} /$ ml. Sodium fluoride (NaF), 5-fluorotryptophan (FTP) and 3-aminopropylphosphonate (3-APP) were obtained from Sigma (Poole, Dorset, UK). Carbogen gas $(95 \%$ $\mathrm{O}_{2}, 5 \% \mathrm{CO}_{2}$ ) was obtained from BOC Ltd (Guildford, Surrey, UK).

Animals and tumour models Rat prolactinoma (GH3) tumours in MF1 nude mice and rat hepatoma (H9168a) tumours in Buffalo rats were grown s.c. in the flanks of animals as previously described [28, 36]. Tumour volume was determined by measuring three orthogonal dimensions and using the formula $(\pi /$ 6) $\times l \times w \times h$, and they were used for studies when $0.5-1 \mathrm{~g}$ (mice) or $2-8 \mathrm{~g}$ (rats). All MR studies utilised a Varian 200/330 4.7-T horizontal bore spectrometer with animals positioned so that tumours hung freely into a surface coil. Body temperature was maintained at 36$37^{\circ} \mathrm{C}$ with a warmed water pad.

Protocol used for ${ }^{19} \mathrm{~F}$ and ${ }^{31} P$-MRS studies of mice bearing GH3 xenografts MF1 nude mice (ca. $30 \mathrm{~g}$ ) were anaesthetised with Hypnorm/Hypnovel $(0.3 \mathrm{ml}$ i.p. of $12.5 \mathrm{mg} / \mathrm{kg}$ midazolam, $25 \mathrm{mg} / \mathrm{kg}$ fluanisone and $0.8 \mathrm{mg} / \mathrm{kg}$ fentanyl citrate in water) and tumours suspended into an $18 \mathrm{~mm}$ surface coil tunable to both ${ }^{31} \mathrm{P}$ and ${ }^{19} \mathrm{~F}$. The coil was tuned to ${ }^{1} \mathrm{H}$ so that the shimming was performed over the same volume as the spectroscopy. The experimental set-up for this tumour model was as previously described [19] and included a bulb containing $100 \mu \mathrm{l}$ of $15 \mathrm{mM}$ FTP $(1,500 \mathrm{nmoles})$ positioned $5 \mathrm{~mm}$ under the coil as an external ${ }^{19} \mathrm{~F}$ standard. The animals were fitted with a nose-piece equipped with a scavenger so that they could breathe air or carbogen which was supplied at a rate of $21 / \mathrm{min}$. First, while the animals breathed air, a 5 min ${ }^{31} \mathrm{P}$-spectrum $(246 \times 1.2 \mathrm{~s}$ transients using a $90^{\circ}$ flip-angle with a spectral width of $8 \mathrm{kHz}$ ) was obtained. The gas supply was then switched to carbogen and another $5 \mathrm{~min}{ }^{31} \mathrm{P}$ spectrum acquired. After 19 min of carbogen breathing, 5FU was injected i.p. as a $130 \mathrm{mg} / \mathrm{kg} / 4 \mathrm{ml}$ bolus of $1 \mathrm{~min}$. It is known that a bolus injection i.p. of $125 \mathrm{mg} / \mathrm{kg} 5 \mathrm{FU}$ in $30 \mathrm{~g}$ mice leads to a rapid entrance of 5FU into the blood with a $C_{\max }$ at 4-5 $\min$ [9]. The gas supply was then returned to air for the remainder of the experiment while $11 \times 10 \mathrm{~min}$ consecutive ${ }^{19} \mathrm{~F}$ spectra were acquired $(1,200 \times 0.5 \mathrm{~s}$ transients using a $45^{\circ}$ flip-angle and a spectral width of $25 \mathrm{kHz}$ ), i.e. protocol 1 (see Fig. 1). Finally, a third 5 min ${ }^{31} \mathrm{P}$ spectrum was acquired. Spectra were analysed as previously described using VARPRO $\left({ }^{31} \mathrm{P}\right)$ or FITSPEC $\left({ }^{19} \mathrm{~F}\right)[19]$, with the exception that in this report the ${ }^{19} \mathrm{~F}$-data are presented as nmoles/g of tumour. Corrections were made for the saturation of the signals from the FTP external standard and from 5FU and its metabolites assuming that for all tumours, the $T_{1}$, coil-loading and
Protocol 1: GH3 prolactinoma grown s.c. in MF1 nude mice

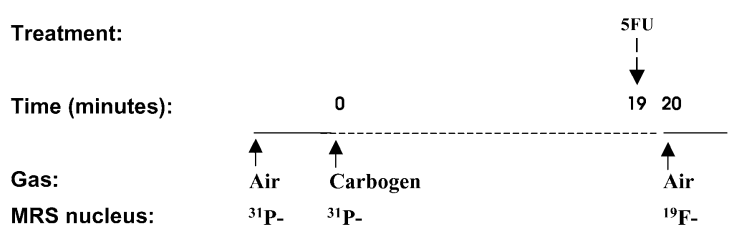

Protocol 2a: Hepatoma 9618a grown s.c. in Buffalo rats



Protocol 2b: Hepatoma 9618a grown s.c. in Buffalo rats

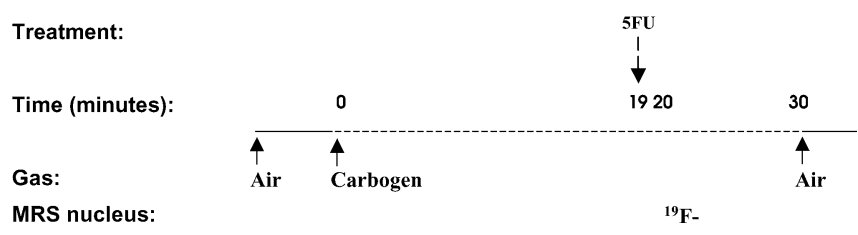

Fig. 1 Protocols for carbogen breathing in the ${ }^{19} \mathrm{~F}$-MRS studies. Gases were supplied at a rate of $21 / \mathrm{min}$. $5 F U(130 \mathrm{mg} / \mathrm{kg} / 4 \mathrm{ml})$ was administered as an i.v. bolus of $1 \mathrm{~min}$ (at $t=19-20 \mathrm{~min}$ ). MRS was performed as described in "Methods"

flip-angle were constant. Under these conditions, the correction factors were 5.0, 2.2, 1.8 and 2.5 for FTP, 5FU, FNuct and FCat (FUPA + FBal), respectively; very similar to those previously described [16].

Protocols used for ${ }^{19} \mathrm{~F}$-MRS studies of rats bearing H9168a hepatomas Rats (ca. $200 \mathrm{~g}$ ) were anaesthetised with an i.p. injection of ca. $0.2 \mathrm{ml}$ Sagatal $(50 \mathrm{mg} / \mathrm{kg})$ and tumours suspended into a $20 \mathrm{~mm}$ surface coil tuned to ${ }^{19} \mathrm{~F}$ with a bulb containing $16 \mu 1$ of $500 \mathrm{mM} \mathrm{NaF}$ $(8,000 \mathrm{nmoles})$ positioned $5 \mathrm{~mm}$ under the coil as an external ${ }^{19} \mathrm{~F}$ standard. Animals breathed air or carbogen as described above. Two different carbogen-breathing protocols were used (Fig. 1). In protocol 2a, the gas supply was switched from air to carbogen and after $19 \mathrm{~min}, 5 \mathrm{FU}$ was injected i.v. as a $100 \mathrm{mg} / \mathrm{kg}$ bolus of $1 \mathrm{~min}$ and the gas supply returned to air for the remainder of the experiment (total carbogen time was $20 \mathrm{~min}$ and thus equivalent to protocol 1 for $\mathrm{GH} 3$ xenografts). Consecutive ${ }^{19} \mathrm{~F}$ spectra of 11 (or in some cases 12$) \times 10 \mathrm{~min}$ were acquired $(1,200 \times 0.5 \mathrm{~s}$ transients using a $45^{\circ}$ flip-angle and a spectral width of $25 \mathrm{kHz}$ ) immediately following 5FU injection. Protocol $2 \mathrm{~b}$ was the same as protocol 2a, but after the same 5FU dose, the carbogen supply was maintained for a further $10 \mathrm{~min}$ before the gas supply was returned to air for the remainder of the experiment (total carbogen time $30 \mathrm{~min})$. Consecutive ${ }^{19} \mathrm{~F}$ spectra $(11 \times 10 \mathrm{~min})$ were then acquired immediately after $5 \mathrm{FU}$ injection. Spectra were 
analysed as described above except that in this case the correction factors were 1.2, 2.1, 2.0, 2.6 and 1.0 for $\mathrm{NaF}$, 5FU, FNuct, FCat (FUPA + FBal) and DHFU, respectively, again making the assumption that for all tumours, the $T_{1}$, coil-loading and flip-angle were constant.

Gradient-recalled echo ${ }^{1} H$-imaging of $\mathrm{GH} 3$ xenografts A separate cohort of six mice bearing GH3 tumours of $0.8-1.2 \mathrm{~g}$ were examined using the doubletuned ${ }^{31} \mathrm{P} /{ }^{19} \mathrm{~F}$ surface coil and set-up described above. Consecutive GRE-images, each of 4 min, were obtained as previously described [19] using a $45^{\circ}$ flip-angle with $\mathrm{TR}=80 \mathrm{~ms}$ and $\mathrm{TE}=20 \mathrm{~ms}$. Animals breathed air for a 16 min which was then switched to carbogen breathing for $16 \mathrm{~min}$, before returning to air breathing for a final period of $16 \mathrm{~min}$.

GRE- ${ }^{1} H$-imaging interleaved with ${ }^{31} P$-spectroscopy of H9168a tumours A 2-turn, $2 \mathrm{~cm}{ }^{1} \mathrm{H} /{ }^{31} \mathrm{P}$ surface coil was used to perform GRE-imaging as described above, except that every $8 \mathrm{~min}$ during the periods of air or carbogen breathing, 4 min non-localised ${ }^{31} \mathrm{P}$-spectra were also obtained before returning to image acquisition. The prior injection of 3-APP $(11 \mathrm{mmol} / \mathrm{kg}$ i.p.) as previously described [23] allowed simultaneous measurements of the effect of carbogen on tumour intracellular and extracellular $\mathrm{pH}\left(\mathrm{pH}_{\mathrm{i}}\right.$ and $\mathrm{pH}_{\mathrm{e}}$, respectively) and $\beta$-NTP/Pi ratios. Animals breathed carbogen for $20 \mathrm{~min}$, and after switching to air, images were acquired for a further $20 \mathrm{~min}$ followed by a final ${ }^{31} \mathrm{P}$ spectrum.

5FU pharmacokinetics in plasma Eight Buffalo rats were anaesthetised as described above and 5FU injected as an i.v. bolus of $100 \mathrm{mg} / \mathrm{kg} / 4 \mathrm{ml}$ via the tail vein. Blood samples of 50-100 $\mu \mathrm{l}$ were taken between $5 \mathrm{~min}$ and 60 min post-injection for four animals, and between $10 \mathrm{~min}$ and $90 \mathrm{~min}$ for the other four animals. The samples were placed in cold heparinised tubes, centrifuged and the plasma supernatant stored at $-20^{\circ} \mathrm{C}$. Plasma levels of $5 \mathrm{FU}$ were determined by gas chromatography linked to mass spectrometry (GC-MS) [24] (see Table 1).

Table 1 Concentrations of $5 \mathrm{FU}$ in rat plasma from $5 \mathrm{~min}$ to 90 min in eight different rats

\begin{tabular}{lll}
\hline Rat number & Sample time (min) & Concentration $5 \mathrm{FU}(\mu \mathrm{M})$ \\
\hline 1 & $13,37,91$ & $1,451,188,15$ \\
2 & $5,13,56$ & $1,928,1,003,100$ \\
3 & $11,20,81$ & $688,491,23$ \\
4 & $9.5,30,93$ & $819,465,120$ \\
5 & $5,20,60.5$ & $790,693,155$ \\
6 & $5.5,19,61.5$ & $800,528,135$ \\
7 & $5.5,20,60$ & $975,525,133$ \\
8 & $10.5,20,90$ & $734,514,18$
\end{tabular}

Non-tumour-bearing Buffalo rats were injected with $100 \mathrm{mg} / \mathrm{kg} /$ $4 \mathrm{ml}$ of $5 \mathrm{FU}$ and blood samples $(50-100 \mu \mathrm{l})$ were taken from the anaesthetised animals and analysed as described in "Methods"
Pharmacokinetic modelling A pharmacokinetic model was fitted to the data on $5 \mathrm{FU}$ in plasma and $5 \mathrm{FU}$ and FNuct in hepatomas in order to distinguish the effect of carbogen on kinetics in plasma from that on kinetics in tumour, and in order to derive the total amount of FNuct formed. Mixed-effects modelling [34] was applied using the program system NONMEM [3]. A similar pharmacokinetic model has been described [25].

5FU kinetics in plasma were described with a linear one-compartment model (Fig. 2, left box). The volume of the central compartment, $V_{1}$ (total body, including plasma but excluding tumour), and the elimination clearance from the central compartment, $\mathrm{CL}_{10}$, were assumed to be related to body weight according to established allometric relationships $[2,40]$.

$V_{1, i}=V_{1}\left(\frac{\mathrm{BW}_{i}}{0.215 \mathrm{~kg}}\right)$

$\mathrm{CL}_{10, i}=\mathrm{CL}_{10}\left(\frac{\mathrm{BW}_{i}}{0.215 \mathrm{~kg}}\right)^{0.75}$

where $V_{1, i}$ and $\mathrm{CL}_{10, i}$ are the expected values of $V_{1}$ and $\mathrm{CL}_{10}$, respectively, in an animal with body weight $=$ $0.215 \mathrm{~kg}, i=1, \ldots$, total number of animals, and $\mathrm{BW}_{i}$ is individual body weight in $\mathrm{kg}(0.215 \mathrm{~kg}$ was the median body weight in this group of rats). Inter-individual random variation was modelled using

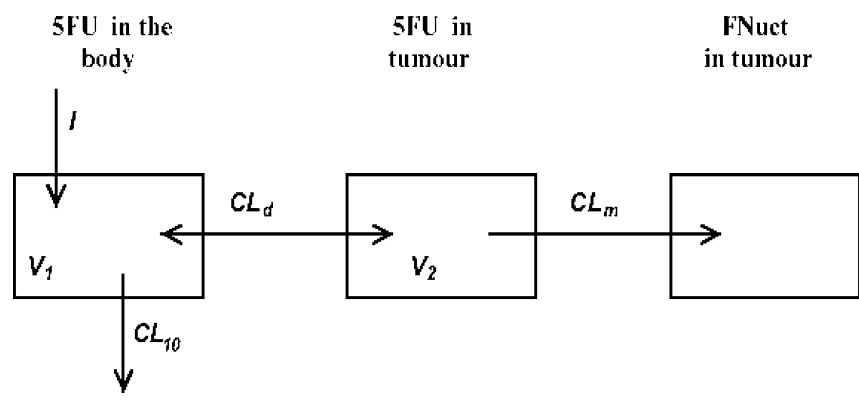

Fig. 2 Linear pharmacokinetic model for 5FU in Buffalo rats bearing $\mathrm{H} 9168$ a hepatomas. 5FU input, I, goes into compartment 1 with volume $V_{1}$ from where it is eliminated via the elimination clearance, $\mathrm{CL}_{10}$. 5FU exchanges between compartment 1 and tumour via the bi-directional distribution clearance $\mathrm{CL}_{\mathrm{d}}$; the distribution volume in tumour is $V_{2}$. FNuct in tumour are formed from $5 \mathrm{FU}$ via the metabolic clearance $\mathrm{CL}_{\mathrm{m}}$. Population parameters of $5 \mathrm{FU}$ pharmacokinetics in the body and in tumour expressed as expected value (EV) and inter-individual standard deviations (iiSD), the typical factor by which EV is multiplied or divided in different individuals, were as follows:

\begin{tabular}{lll}
\hline & $\mathrm{EV}$ & iiSD \\
\hline $\mathrm{V}_{1}(\mathrm{~L})=$ & $0.117 . \mathrm{BW}_{\mathrm{i}} / 0.215 \mathrm{~kg}$ & 1.6 \\
$\mathrm{CL}_{10}(\mathrm{~L} / \mathrm{min})=$ & $4.61 \times 10^{-3} \cdot\left(\mathrm{BW}_{\mathrm{i}} / 0.215\right)^{0.75}$ & 1.2 \\
$\mathrm{~V}_{2}(\mathrm{~L})=$ & $4.15 \times 10^{-3}$ & 1.1 \\
$\mathrm{CL}_{\mathrm{d}}(\mathrm{L} / \mathrm{min})=$ & $2.93 \times 10^{-3}$ & 7.5 \\
$\mathrm{CL}_{\mathrm{m}}(\mathrm{L} / \mathrm{min})=$ & $3.42 \times 10^{-5}$ & 1.6 \\
\hline
\end{tabular}


$V_{1, i}=V_{1, i} \mathrm{e}^{\eta_{1}}$

$\mathrm{CL}_{10, i}=\mathrm{CL}_{10, i} \mathrm{e}^{\eta_{2}}$

where $V_{1, i}$ and $\mathrm{CL}_{10, i}$ are the true central distribution volume and the elimination clearance of animal no. $i$ and $\eta_{1}, \eta_{2}$ are random variables with mean zero and variance $\omega_{1}{ }^{2}$ and $\omega_{2}{ }^{2}$, respectively. Inter-individual standard deviations (iiSD in Table 2) were calculated as $\mathrm{e} \sqrt{ } \omega^{2}$. The residual coefficient of variation was assumed to be proportional to the square root of the model prediction (i.e. CV decreases with increasing predicted concentration):

$y_{i j}=\ddot{y}_{i j}+\sqrt{ } \ddot{y}_{i j} \times \varepsilon_{i j}$

where $y_{i j}$ is the measured concentration in animal no. $i$ at time $j(j=1, \ldots$, total number of measuring time points in animal $i$ ), $\ddot{y}_{i j}$ is the model prediction based on $V_{1, i}$ and $\mathrm{CL}_{10, i}$, and $\epsilon_{i j}$ is a random variable with mean zero and variance $\omega^{2}$.

The above model for 5FU kinetics in plasma was incorporated in a linear three-compartment population model for 5FU and FNuct in the hepatoma-bearing rats (Fig. 2, all three boxes). The population parameters describing $5 \mathrm{FU}$ in plasma $\left(V_{1}, \mathrm{CL}_{10}, \omega_{1}{ }^{2}, \omega_{2}{ }^{2}\right)$ were kept fixed as estimated from the rat group where plasma samples had been taken. The measuring time points for the NMR data were taken to be the midpoints of the 10 min spectral acquisition periods. The inter-individual variance model for the tumour parameters was of the same form as the one for the central compartment parameters:

$V_{2, i}=V_{2} \mathrm{e}^{\eta_{3}}$

$\mathrm{CL}_{\mathrm{d}, i}=\mathrm{CL}_{\mathrm{d}} \mathrm{e}^{\eta_{4}}$

$\mathrm{CL}_{\mathrm{m}, i}=\mathrm{CL}_{\mathrm{m}} \mathrm{e}^{\eta_{5}}$

where $V_{2}$ is the distribution volume of 5FU in tumour, $\mathrm{CL}_{\mathrm{d}}$ is the (bi-directional) distribution clearance of $5 \mathrm{FU}$ between the central compartment and tumour, $\mathrm{CL}_{\mathrm{m}}$ is the metabolic clearance governing the conversion of $5 \mathrm{FU}$ into FNuct, and $\eta_{3}, \eta_{4}, \eta_{5}$ are random variables with mean zero and variances $\omega^{2}, \omega_{4}{ }^{2}$ and $\omega_{5}{ }^{2}$, respectively. The residual variance model was also the same as with the plasma data (Eq. 6). After fitting the population parameters using NONMEM (see "Results": Table 2), empirical Bayes estimates of the individual parameters $V_{1, i}, \mathrm{CL}_{10, i}, \quad V_{2, i}, \mathrm{CL}_{\mathrm{d}, i}$ and $\mathrm{CL}_{\mathrm{m}, i}$ were obtained using NONMEM's POSTHOC function (Note that keeping the population parameters of central compartment 5FU kinetics $\left(V_{1}, \mathrm{CL}_{\mathrm{e}}, \omega_{1}{ }^{2}, \omega_{2}{ }^{2}\right)$ fixed does not preclude estimating individual $\eta$ s on $V_{1}$ and $\mathrm{CL}_{10}$ for each of the tumour-bearing animals so that each one is allowed to have its unique set of parameters $V_{1, i}, \mathrm{CL}_{10, i}$, $\mathrm{V}_{2, i}, \mathrm{CL}_{\mathrm{d}, i}, \mathrm{CL}_{\mathrm{m}, i}$ describing $5 \mathrm{FU}$ pharmacokinetics in plasma as well as in tumour). The explicit solutions for the model predictions for compartments 1-3 can be derived by applying Laplace transformations and the partial fractions theorem $[4,21]$. The result is:

$$
\begin{aligned}
C_{1}(t)= & \left(\frac{D}{V_{1}}\right) \mathrm{e}^{-k_{10} t} \\
A_{2}(t)= & \left(\frac{D k_{12}}{E_{2}-k_{10}}\right)\left(\mathrm{e}^{-k_{10} t}-\mathrm{e}^{-E_{2} t}\right) \\
A_{3}(t)= & D k_{12} k_{23}\left(\frac{\mathrm{e}^{-k_{10} t}}{E_{2}-k_{10}}\right)\left(k_{30}-k_{10}\right) \\
& +\mathrm{e}^{-E_{2} t}\left(k_{10}-E_{2}\right)\left(k_{30}-E_{2}\right) \\
& +\mathrm{e}^{-k_{30} t}\left(k_{10}-k_{30}\right)\left(E_{2}-k_{30}\right)
\end{aligned}
$$

where $C_{1}$ is $5 \mathrm{FU}$ concentration in the central compartment, $D$ is dose, $A_{2}$ is the amount of 5FU in tumour, $A_{3}$ is the amount of FNuct in tumour, $k_{10}=\mathrm{CL}_{10} / V_{1}$, $k_{12}=\mathrm{CL}_{\mathrm{d}} / V_{1}, \quad k_{23}=\mathrm{CL}_{\mathrm{m}} / V_{2}, E_{2}=\mathrm{CL}_{\mathrm{d}} / V_{2}+k_{23}$, and $k_{30}$ is the rate of elimination of FNuct from tumour. Letting $k_{30}$ float (as opposed to fixing it to zero) produced no significant improvement of fit so that it was fixed to zero in the final fit.

The area under the amount-time curve of 5FU in tumour from time zero to time infinity was computed using:

$$
\int_{0}^{\infty} A_{2}(t) \mathrm{d} t=\frac{D k_{12}}{E_{2}}-k_{10}\left(\frac{1}{k_{10}}-\frac{1}{E_{2}}\right)
$$

The total amount of nucleotides formed from time zero to time infinity is this area multiplied by $k_{23}$

$$
A_{3, \text { total }}=k_{23}\left(\frac{D k_{12}}{E_{2}-k_{10}}\right)\left(\frac{1}{k_{10}}-\frac{1}{E_{2}}\right)
$$

Table 2 Summary of parameter estimates in pharmacokinetic model for different gas-breathing protocols in H9168a tumours grown in Buffalo rats

\begin{tabular}{lllllll}
\hline Gas & $V_{1}(1)$ & $V_{2}\left(1 \times 10^{-3}\right)$ & $\mathrm{CL}_{10}\left(1 / \min \times 10^{-3}\right)$ & $\mathrm{CL}_{\mathrm{d}}\left(1 / \mathrm{min} \times 10^{-3}\right)$ & $\mathrm{CL}_{\mathrm{m}}\left(\mathrm{l} / \mathrm{min} \times 10^{-5}\right)$ & $t_{1 / 2}{ }^{5 \mathrm{FU}}(\mathrm{min})$ \\
\hline Air $(n=5)$ & $0.167 \pm 0.051$ & $4.17 \pm 0.03$ & $4.08 \pm 0.1$ & $2.27 \pm 2.72$ & $3.42 \pm 2.0$ \\
Carbogen 2a $(n=4)$ & $0.131 \pm 0.064$ & $4.16 \pm 0.08$ & $4.49 \pm 0.84$ & $11.53 \pm 10.87$ & $4.11 \pm 0.8$ & 27.6 \\
Carbogen 2b $(n=4)$ & $0.138 \pm 0.06$ & $4.11 \pm 0.04$ & $5.26 \pm 0.35$ & $2.61 \pm 1.79$ & $4.02 \pm 2.48$ & 20.3 \\
\hline
\end{tabular}

Results show the mean $\pm \mathrm{SD}$ of estimates of compartment volumes $V_{1}$ and $V_{2}$, and the clearance from these compartments from $(n)$ animals 


\section{Statistics}

All data are presented as the mean \pm SEM, except where stated (e.g. Table 2). Estimation of the apparent rate of elimination of 5FU from $\mathrm{GH} 3$ xenografts was determined from a semi-log plot of peak integral versus time to provide a $t_{1 / 2}$. Statistical analysis utilised a $t$-test or a paired $t$-test where appropriate.

\section{Results}

Concentrations of $5 F U$ in rat plasma Table 1 summarises the individual plasma measurements of 5FU made in eight different rats. This data were used in the linear one-compartment model of plasma pharmacokinetics (Fig. 2) [(see "Methods")].

Effect of carbogen on 5FU uptake and metabolism in H9618a hepatomas The uptake and metabolism of $5 \mathrm{FU}(130 \mathrm{mg} / \mathrm{kg})$ by $\mathrm{H} 9618 \mathrm{a}$ tumours in air-breathing animals is shown in Fig. 3a. The mean 5FU $C_{\max }$ determined at $5 \mathrm{~min}$ was $631 \pm 115 \mathrm{nmoles} / \mathrm{g}$ of tumour, which declined with a $t_{1 / 2}$ of $31.7 \pm 1.5 \mathrm{~min}$ and in most cases remained detectable at $100 \mathrm{~min}$. Metabolism to the FNuct was rapid since this signal was immediately detectable. 5-fluorocatabolites (FCat), including occasionally very low levels of the first metabolite of catabolism, dihydro-fluorouracil (DHFU), were also detectable within $10 \mathrm{~min}$ and total catabolite gradually increased throughout the experiment. Tumour uptake and metabolism of $5 \mathrm{FU}$ in carbogen-breathing rats is shown in the accompanying Fig. 3b,c using the two different protocols described in "Methods", and a further analysis of this data is summarised in Table 3. Although the 5FU $C_{\max }$ was unaffected, carbogen significantly increased the rate of elimination of $5 \mathrm{FU}$ from the tumour (decreased the $t_{1 /}$ 2) to $20.7 \pm 4.8 \mathrm{~min}(p=0.007)$ and $17.9 \pm 3.8 \mathrm{~min}$ $(p=0.0003)$ for the protocols $2 \mathrm{a}$ and $2 \mathrm{~b}$, respectively (Table 3). The amount of FNuct formed after $100 \mathrm{~min}$ was not significantly affected by either protocols, nor when the carbogen data were pooled $(p=0.11)$. However, the FNuct AUC was significantly increased (by $62 \%$ ) in protocol $2 \mathrm{a}$, although not in protocol $2 \mathrm{~b}$, and pooling the carbogen data also did not lead to a significant effect $(p=0.13)$. Nevertheless, this increase seen in protocol 2a suggested some impact on FNuct metabolism, and using the mean 5FU/FNuct AUC ratio to control for the fact that less $5 \mathrm{FU}$ was present in carbogen-tumours it was apparent that carbogen significantly increased this ratio from 0.55 in airbreathing animals to 0.89 and 0.80 for carbogen protocols $2 \mathrm{a}$ and $2 \mathrm{~b}$, respectively (Table 3 ). This was significant for protocol $2 \mathrm{a}(p=0.042)$ and for the pooled data $(p=0.029)$, but not for $2 \mathrm{~b}(p=0.1)$. There was no evidence for a significant impact by carbogen on the presence of the fluorocatabolites.
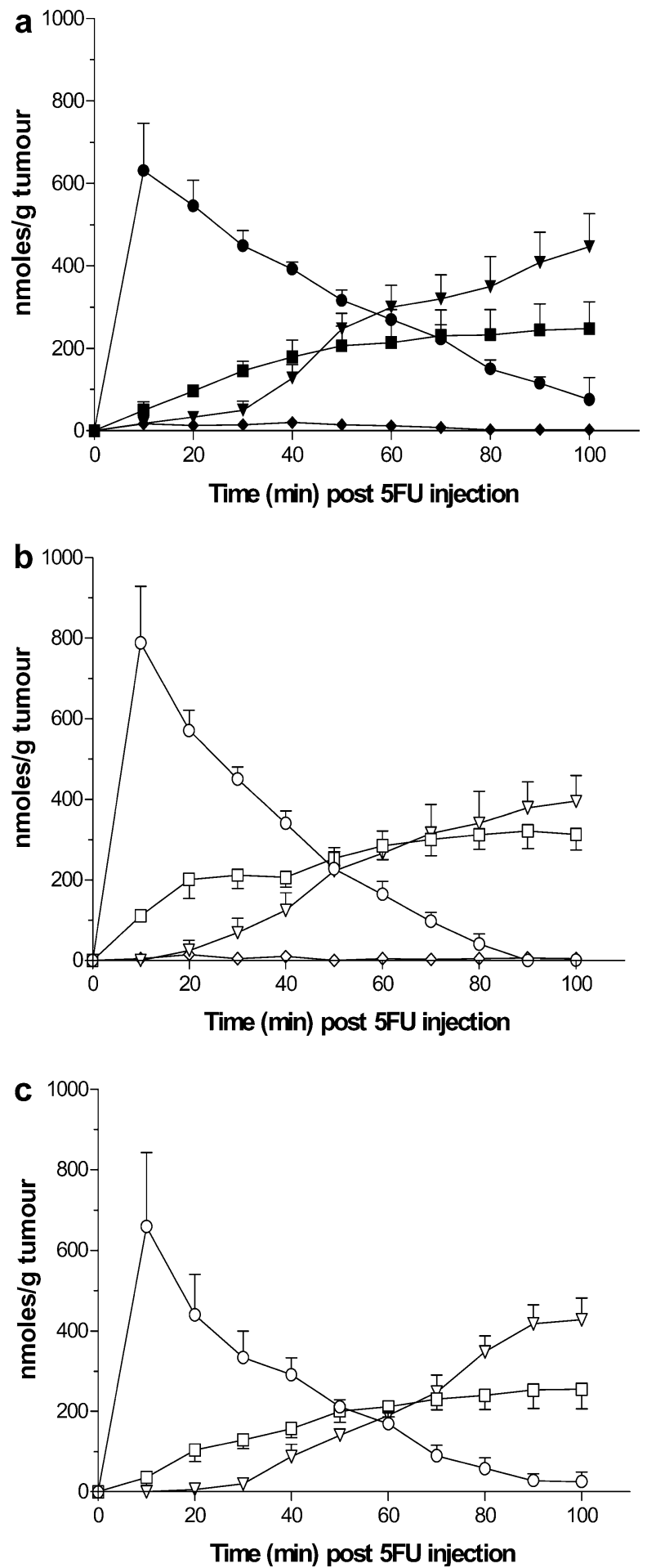

Fig. 3 Influence of host carbogen breathing on the uptake and metabolism of 5FU in $\mathrm{H} 9618$ a hepatomas grown s.c. in rats. 5FU was administered as an i.v. bolus of $130 \mathrm{mg} / \mathrm{kg} / 4 \mathrm{ml}$. Results show the mean \pm SEM from a air-breathing animals $(n=5$, closed symbols), b carbogen-breathing animals $(n=4)$ undergoing protocol 2a (open symbols) and c carbogen-breathing animals $(n=4)$ undergoing protocol $2 \mathrm{~b}$ (open symbols), 5FU (filled circle), FNuct (filled square), FUPA + FBal (filled down triangle), DHFU (filled diamond). From a semi-log plot of the $5 \mathrm{FU}$ curve, the $t_{1 / 2}$ for $5 \mathrm{FU}$ was calculated to be $31.7 \pm 1.5$ (a), 20.7 \pm 4.8 (b) and $17.9 \pm 3.8 \min (\mathbf{c})$ 
Table 3 Summary of effect of carbogen breathing on 5FU uptake and metabolism in H9168a hepatomas grown s.c. in Buffalo rats

\begin{tabular}{lllllll}
\hline Gas $(n)$ & $\begin{array}{l}5 \mathrm{FU} t_{1 / 2} \\
(\mathrm{~min})\end{array}$ & $\begin{array}{l}5 \mathrm{FU} C_{\max } \\
(\mathrm{nmoles} / \mathrm{g})\end{array}$ & $\begin{array}{l}\text { 5FU AUC } \\
(\mu \mathrm{moles} / \mathrm{g})\end{array}$ & $\begin{array}{l}\text { FNuct AUC } \\
(\mu \mathrm{moles} / \mathrm{g})\end{array}$ & $\begin{array}{l}\text { FNuct, } \\
\text { at 100 min } \\
(\mathrm{nmoles} / \mathrm{g})\end{array}$ & $\begin{array}{l}\text { FCat } \\
\text { AUC } \\
(\mu \mathrm{moles} / \mathrm{g})\end{array}$ \\
\hline Air (5) & $31.7 \pm 1.5$ & $631 \pm 115$ & $31.3 \pm 4.6$ & $17.3 \pm 3.9$ & $248 \pm 65$ & $20.8 \pm 3.3$ \\
Crb-2a (4) & $20.7 \pm 4.8^{*}$ & $788 \pm 141$ & $26.8 \pm 2.7$ & $23.6 \pm 2.5^{* *}$ & $313 \pm 39$ & $\begin{array}{l}\text { FNuct/5FU } \\
\text { AUC ratio }\end{array}$ \\
Crb-2b (4) & $17.9 \pm 3.7^{*}$ & $659 \pm 184$ & $22.9 \pm 4.7$ & $16.9 \pm 2.4$ & $255 \pm 49$ & $17.7 \pm 3.0$ \\
All Crb (8) & $19.3 \pm 1.6^{*}$ & $723 \pm 110$ & $24.9 \pm 2.6$ & $20.2 \pm 2.1$ & $284 \pm 31$ & $0.89 \pm 0.13$ \\
\hline
\end{tabular}

Buffalo rats bearing H9168a hepatomas breathed either air or carbogen gas using the protocols described in "Methods" (see also Fig. 1). Data show mean \pm SEM for $(n)$ animals calculated from the graphs shown in Fig. 3. The $5 \mathrm{FU} t_{1 / 2}$ was determined from a

semi-log plot of the data and the area under the curve (AUC) was determined using the trapezoidal rule. Mean values were compared using Student's $t$-test, where $* p<0.001$ and $* * p<0.05$ significantly signify different to air-breathing animals

Pharmacokinetic model Using the one-compartment model described in "Methods" (Fig. 2), for the individual H9168a tumour data, the population parameters of 5FU kinetics in plasma and tumour and of FNuct formation in tumour are summarised in Table 2 for airbreathing and carbogen-breathing rats. The coefficients of variation of the parameter estimates are 6, 39 and $35 \%$ for $V_{2}, \mathrm{CL}_{\mathrm{d}}$ and $\mathrm{CL}_{\mathrm{m}}$, respectively, and are 1,300, 170 and $72 \%$ for the corresponding estimates of interindividual random variance. Bayesian estimation of individual parameters resulted in a satisfactory description of the data for 5FU and FNuct formation in tumour in all 13 individual tumours (5 air and 8 carbogens). The period of 5FU entrance into tumour could be seen in three out of five air-controls while it was already over in all carbogen-treated animals at the time the first spectrum was completed (10 min post-injection of $5 \mathrm{FU})$. The rate of elimination of $5 \mathrm{FU}$ from the tumour reflected its elimination from plasma in all but one of the eight carbogen-breathing animals (protocol $2 b$ ).

All individual H9168a hepatoma data are summarised in Fig. 4 and Table 2 for air-breathing and carbogen-breathing animals using the two slightly different carbogen protocols $2 \mathrm{a}$ and $2 \mathrm{~b}$. Both carbogen protocols tended to decrease the $t_{1 / 2}$ for elimination of $5 \mathrm{FU}$ from the tumour (Table 2), confirming the data shown in
Fig. 4 Pharmacokinetic parameters for $5 \mathrm{FU}$ in airbreathing Buffalo rats bearing H9168a hepatomas compared to two different carbogen breathing protocols. 5FU was administered as an i.v. bolus of $130 \mathrm{mg} / \mathrm{kg} / 4 \mathrm{ml} . \eta$ on $V_{1}$ : individual deviation from the expected (weight-dependent) central 5FU distribution volume as estimated from plasma samples in a different group of rats. $\eta$ on $\mathrm{CL}_{10}$ : same for the 5FU elimination clearance from the central compartment. $V_{2}: 5 \mathrm{FU}$ distribution volume in tumour. $\mathrm{CL}_{\mathrm{d}}$ : bi-directional distribution clearance for $5 \mathrm{FU}$ between central compartment and tumour. $\mathrm{CL}_{\mathrm{m}}$ : metabolic clearance for conversion of $5 \mathrm{FU}$ to FNuct in tumour. Symbols defined as: filled square, air breathing; filled triangle, carbogen breathing (protocol 2a); and filled down triangle, carbogen breathing (protocol 2b)
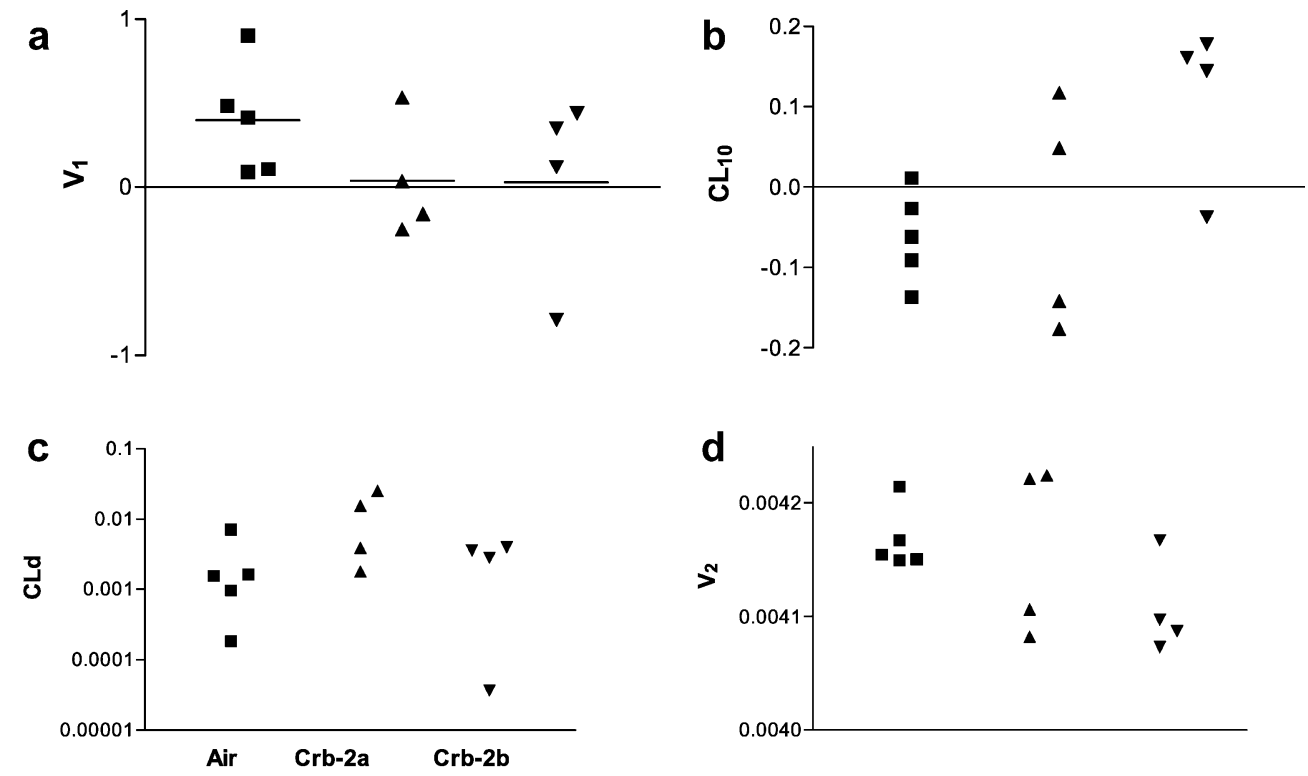

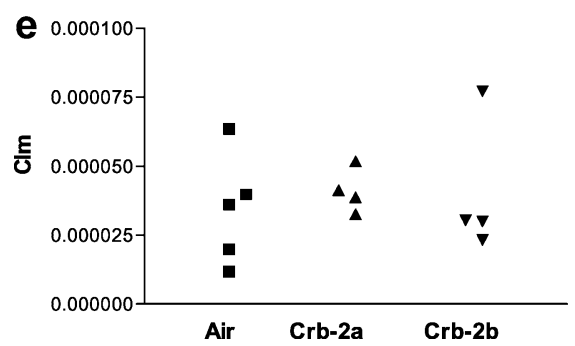


Table 3. There was a trend for carbogen to decrease the central 5FU distribution volume, $V_{1}$ (Fig. 4a) and to increase clearance of $5 \mathrm{FU}$ from the plasma, $\mathrm{CL}_{10}$ (Fig. 4b). The parameter estimates appeared to suggest that carbogen protocol $2 \mathrm{a}$ accelerated the exchange of $5 \mathrm{FU}$ between plasma and tumour as indicated by a raised $\mathrm{CL}_{\mathrm{d}}$ (Fig. 4c), but it was not possible to fit a parameter to describe this increase, probably because 5FU entrance into tumour was too rapid to be directly observable. In three of four animals, carbogen protocol $2 \mathrm{~b}$ also appeared to increase $\mathrm{CL}_{\mathrm{d}}$ although to a lesser extent than protocol 2a (Fig. 4c). Carbogen did not induce any partitioning of 5FU into tumour, as demonstrated by the lack of an effect on the apparent distribution volume in tumour, $V_{2}$ (Fig. 4d). Accordingly, consistent with the analysis summarised in Table 3 , the tumour $5 \mathrm{FU}-\mathrm{AUC} \mathrm{C}_{\alpha}$ remained unchanged, and there was also no effect on the total amount of FNuct formed (data not shown). The modelling did not show a clear trend for the carbogen protocols to increase $\mathrm{CL}_{\mathrm{m}}$, i.e. the rate of FNuct formation (Fig. 4e, Table 2).

Effect of carbogen on $5 F U$ uptake and metabolism in GH3 xenografts $5 \mathrm{FU}$ uptake was very variable in these tumours. The mean $C_{\max }$ of $801 \pm 262 \mathrm{nmoles} / \mathrm{g}$ at $10 \min (n=5)$ of air-breathing controls was similar to that observed in the H9618a hepatomas, the 5FU signal then decreased with a $t_{1 / 2}{ }^{5 \mathrm{FU}}$ of $19.3 \pm 3.8 \mathrm{~min}$ and was rarely detectable after $90 \mathrm{~min}$. FCat were visible immediately and reached values as high as the $5 \mathrm{FU} C_{\max }$, while in contrast, the FNuct signal did not appear until 30 min (Fig. 5a). DHFU was never detected. Figure 5 demonstrates that on average, carbogen had very little effect on 5FU uptake and metabolism in GH3 tumours. The mean 5 FU $C_{\max }$ of $730 \pm 105$ nmoles/g of carbogenbreathing animals was not significantly different from controls, although it occurred later at $20 \mathrm{~min}$, and $5 \mathrm{FU}$ then decreased rapidly with a $t_{1 / 2} 5 \mathrm{FU}$ of $14.1 \pm 1.4 \mathrm{~min}$ ( $p=0.25$ compared to controls). In an attempt to counter the variability within the model, the areas under the curves (AUC) shown in Fig. 5 for 5FU and metab- olites were measured to allow comparisons between air-breathing and carbogen-breathing animals, but no significant differences were detected (data not shown). In addition, the mean FNuct/5FU AUC ratio of $0.3 \pm 0.08$ was not significantly increased compared to the airbreathing controls of $0.27 \pm 0.11$. This FNuct/5FU AUC ratio was ca. half that determined in H9168a hepatomas (see above) which confirmed that GH3 tumours produced relatively little FNuct.

As $5 \mathrm{FU}$ uptake was very variable between different $\mathrm{GH} 3$ xenografts, it was possible that small but biologically significant effects of carbogen on 5FU pharmacokinetics might be masked. To investigate this possibility, three tumour-bearing animals received a double-dose of $5 \mathrm{FU}$, the second dose given $2 \mathrm{~h}$ after the first injection, i.e. about $30 \mathrm{~min}$ after the first $5 \mathrm{FU}$ dose was no longer detectable by ${ }^{19} \mathrm{~F}$-MRS. In one tumour, the $5 \mathrm{FU} C_{\max }$ was doubled, and 5FU was then eliminated at the standard rate. However, in two other GH3 tumours, the $C_{\max }$ in air-breathing and carbogen-breathing animals was the same (results not shown). These experiments underscored the variability of the GH3 tumour model.

Effects of carbogen on tumour physiology A switch from air to carbogen breathing rapidly induced an increase in the normalised GRE-image intensity of both H9168a (Fig. 6a) and GH3 tumours (Fig. 6b). The maximum increase was more variable in $\mathrm{GH} 3 \mathrm{~s}$ than H9168a, but the mean increase of ca. $60 \%$ was similar, and was sustained as long as the animals breathed carbogen. On returning to air breathing, the image intensity decreased slowly so that in both tumour types it remained significantly raised $(p<0.05)$ more than 16 min later.

In GH3 xenografts, carbogen had no effect on the energy state (B-NTP/Pi ratio) [(results not shown)], but significantly increased this ratio in H9168a hepatomas, which was reversed on switching to air breathing (Table 4). In GH3 xenografts the $\mathrm{pH}$ was not measured, while in the hepatomas, carbogen breathing caused a significant increase in the mean transmembrane negative
Fig. 5 Influence of host carbogen breathing on the uptake and metabolism of $5 \mathrm{FU}$ in s.c. $\mathrm{GH} 3$ xenografts. $5 \mathrm{FU}$ was administered as an i.v. bolus of $130 \mathrm{mg} / \mathrm{kg} / 4 \mathrm{ml}$. Results show the mean \pm SEM $(n=5)$ from air-breathing animals (closed symbols) and carbogen-breathing animals (open symbols), 5FU (filled circle), FNuct (filled square), FUPA + FBal (filled down triangle), DHFU (filled diamond). From a semi-log plot of the $5 \mathrm{FU}$ curve, the $t_{1 / 2}$ for $5 \mathrm{FU}$ was calculated to be a $19.3 \pm 3.8 \mathrm{~min}$ and $\mathbf{b}$ $14.1 \pm 1.4 \mathrm{~min}$



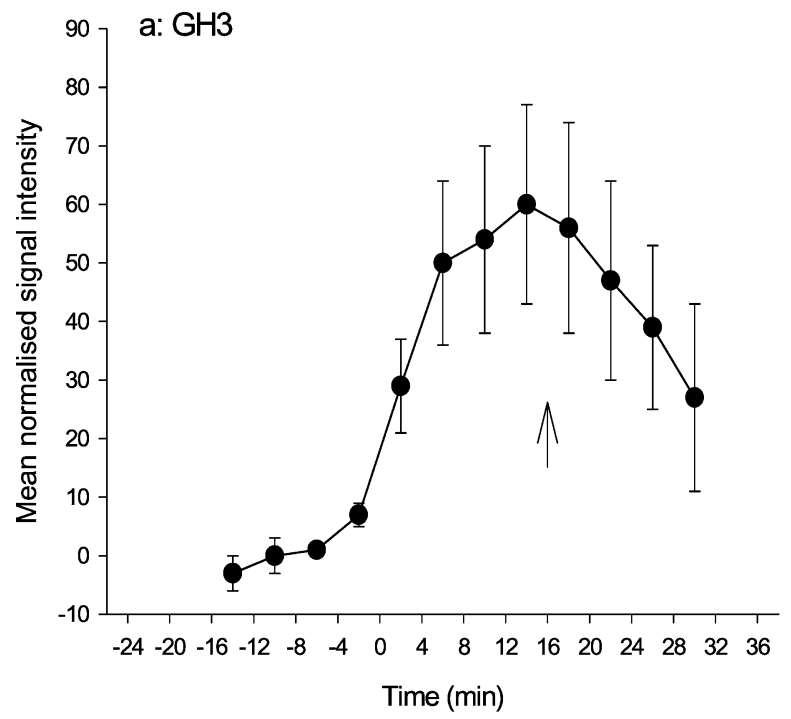

Fig. 6 Effects of carbogen on the GRE- ${ }^{1} \mathrm{H}$-image intensity of rodent tumours. Nude mice bearing s.c. GH3 tumours and Buffalo rats bearing s.c. H9168a hepatomas breathed air until time zero, before switching to carbogen gas for $16 \mathrm{~min}$ or $20 \mathrm{~min}$ (arrow), and then returning to air breathing. Results show the mean \pm SEM normalised signal intensity from six animals (GH3 xenograft) and four animals (H9168a hepatomas)

$\mathrm{pH}$ gradient $(-\Delta \mathrm{pH})$ of 0.11 units via a decrease in the $\mathrm{pH}_{\mathrm{e}}$. On switching back to air, the $-\Delta \mathrm{pH}$ returned to the pre-treatment value.

\section{Discussion}

The results in this paper using two different rodent tumour models show that carbogen breathing can have profound and varied effects on aspects of tumour physiology such as energy status, $\mathrm{pH}$ and blood flow and oxygenation (in the guise of FLOOD) which may impact upon uptake and retention by the tumour of the anticancer drug 5FU. Our analysis suggests that carbogen can rapidly increase drug uptake from the plasma, but simultaneously increases drug elimination from the tumour. Thus, unless there is a secondary mechanism trapping $5 \mathrm{FU}$ in the tumour space, for example a change

Table 4 Effect of carbogen on hepatoma $\mathrm{pH}$ and $\beta$-NTP/Pi ratios

\begin{tabular}{lllll}
\hline $\begin{array}{l}\text { Time } \\
\text { period }\end{array}$ & $\beta-\mathrm{NTP} / \mathrm{Pi}$ & $\mathrm{pH}_{\mathrm{i}}$ & $\mathrm{pH}_{\mathrm{e}}$ & $\Delta \mathrm{pH}$ \\
\hline Before & $0.74 \pm 0.08$ & $7.17 \pm 0.03$ & $6.93 \pm 0.05$ & $-0.27 \pm 0.07$ \\
During & $1.10 \pm 0.09^{*}$ & $7.15 \pm 0.02$ & $6.79 \pm 0.05^{* *}$ & $-0.38 \pm 0.11^{* *}$ \\
After & $0.83 \pm 0.09$ & $7.19 \pm 0.03$ & $6.96 \pm 0.07$ & $-0.26 \pm 0.14$ \\
\hline
\end{tabular}

Buffalo rats bearing H9168a hepatomas breathed air for $24 \mathrm{~min}$ prior to switching to carbogen gas for $20 \mathrm{~min}$ and then returning to air for $16 \mathrm{~min}$. Results show the mean \pm SEM from four tumours, where $* p<0.02$ and $* * p<0.01$ compared to before carbogen breathing using a paired $t$-test

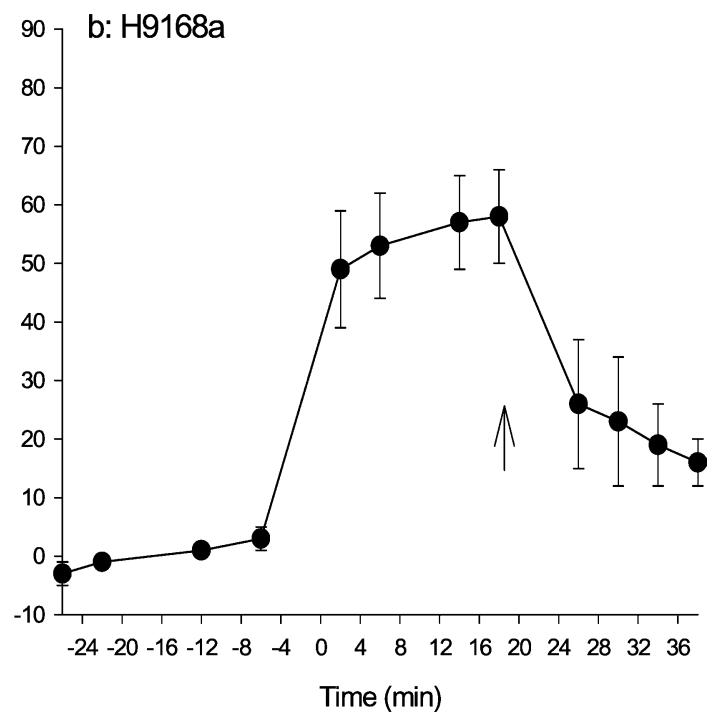

in $\mathrm{pH}$ or stimulation of $5 \mathrm{FU}$ anabolism, carbogen breathing may not necessarily increase the AUC in tumours.

Breathing of carbogen gas $\left(95 \% \mathrm{O}_{2}, 5 \% \mathrm{CO}_{2}\right)$ is known to have profound effects on both host and tumour physiology, which include increased $\mathrm{O}_{2}$ dissolved in the blood and host vessel vasoconstriction, but also increased tumour blood vessel dilation via the $\mathrm{CO}_{2}$ component [33]. GRE- ${ }^{1} \mathrm{H}$-imaging has been used to detect rapid and reversible increases in the image intensity of some tumours in response to carbogen and this has been shown in GH3 tumours grown in rats to reflect primarily increases in tumour blood oxygenation and volume, as well as discrete increases in tumour blood flow [10, 29, 30]. The effects detected on tumour blood flow suggested that carbogen could be used to increase the delivery of chemotherapeutic agents to solid tumours which can suffer from a poor blood supply. We confirmed this hypothesis in two different tumour models. In GH3 tumours grown in rats, carbogen increased the uptake of i.v. injected ifosfamide but did not affect the rate of elimination, so that overall drug retention was increased [31]. In large hypoxic murine RIF-1 tumours (2-3 g or 7-10\% body-weight), carbogen increased the uptake of i.p injected 5FU and reduced elimination, so that retention and metabolism of $5 \mathrm{FU}$ was markedly increased [19]. However, carbogen had no significant effect on 5FU uptake and metabolism in small RIF-1 tumours $(0.8-1.6 \mathrm{~g}$ or $2.5-5 \%$ body-weight). These observations suggest the effects of carbogen on tumours may not be universal, and indeed different research groups using different tumour models have observed no change as well as both implied and real increases and decreases in tumour oxygenation, blood flow, $\mathrm{pH}$ and energy status $[1,6,8,12,14,15,28$, 39]. We decided therefore to investigate the effects of carbogen on the pharmacokinetics of $5 \mathrm{FU}$ in two additional rodent tumour models, which have shown significant physiological responses to carbogen [29, 35]. The tumour sizes studied were relatively small (i.e. \% 
body-weight was $2-4 \%$ ), but the hypoxia status was not determined, and one cannot assume that tumour size always correlates positively with tumour hypoxia across all tumour types.

Consistent with previous observations on two different rat mammary carcinomas, as well as H9168a hepatoma and GH3 prolactinoma in rats or xenografted into nude mice [28], carbogen breathing immediately induced a rapid increase in the mean GRE-image intensity to values ca. $50 \%$ greater than baseline. In the experiments described in this report, images were also acquired after carbogen breathing was discontinued, and this showed that the effect was not rapidly reversible as first described in the GH3 tumour grown in rats [27]. In both tumour models used in this study, the mean image intensity remained significantly raised 16-20 min after the switch to air breathing. We have not explored if this persistent raised image intensity reflects increased tumour blood flow or oxygenation or both, although studies of GH3 tumours in rats showed that a significant proportion of the change in GRE-image intensity could be due to flow [10]. Thus, although a carbogen-induced increase in tumour blood flow/blood volume assessed by GRE-MRI would increase drug delivery, the slow return to baseline following the return to air breathing may have allowed an equally rapid elimination of $5 \mathrm{FU}$ from the tumour space, unless some other mechanism trapped the drug in the tumour. Indeed, this hypothesis is consistent with the lack of significant effect of carbogen on the mean $5 \mathrm{FU} C_{\max }$ at 5-10 min or 5FU AUC in either of the two tumour models used in this study.

The GH3 xenograft described in this paper appeared variable in its behaviour with respect to both $5 \mathrm{FU}$ uptake and the maximum change in GRE-MRI image intensity, and this may have disguised the fact that some GH3 tumours could respond positively to carbogen in terms of the $5 \mathrm{FU} C_{\max }$. As $5 \mathrm{FU}$ was eliminated very quickly from this tumour, it was possible to provide a second 5FU dose $90 \mathrm{~min}$ after the first dose, thus allowing a single tumour to act as its own control. In one tumour, this experiment clearly demonstrated that carbogen could increase the $5 \mathrm{FU} C_{\max }$, but in two other tumours there was no effect. Thus, on average there was no significant effect of carbogen on the uptake and/or metabolism of $5 \mathrm{FU}$ in the GH3 xenograft.

In Buffalo rats, the hosts for the 9618a Hepatoma, the pharmacokinetic modelling based upon plasma and ${ }^{19} \mathrm{~F}$-MRS data showed that carbogen breathing prior to $5 \mathrm{FU}$ injection caused an increase in the $5 \mathrm{FU} C_{\max }$ in H9168a tumours. Indeed the modelling shows that carbogen protocol $2 \mathrm{a}$ increased the rate of uptake from plasma to tumour $\left(k_{12}\right)$, but also increased the movement in the opposite direction $\left(k_{21}\right)$, i.e. $\mathrm{CL}_{\mathrm{d}}$ increased. Thus, the simple analysis of mean peak heights could not detect a significant increase in $5 \mathrm{FU} C_{\max }$. There was a tendency too for $\mathrm{CL}_{\mathrm{m}}$ to be raised $(20 \%)$ suggesting an acceleration in metabolism of $5 \mathrm{FU}$ to FNuct, although the total FNuct formed was not significantly increased. However, in protocol 2a, the FNuct AUC was signifi- cantly increased as well as the mean AUC ratio of FNuct/5FU (which effectively normalises FNuct formation) compared to air breathing, but not for carbogen protocol $2 \mathrm{~b}$. This suggested the longer period of carbogen breathing was not beneficial for FNuct formation, probably because protocol $2 \mathrm{~b}$ also significantly increased 5FU elimination from the body $\left(\mathrm{CL}_{10}\right.$ was raised). Combining the data for the two carbogen protocols confirmed a significant decrease in the $5 \mathrm{FU} t_{1 / 2}$ from the tumour and an increase in the FNuct/5FU AUC ratio. Thus carbogen breathing had some impact on the rate of FNuct formation which contributed to the faster disappearance of 5FU from the tumours.

Our analysis underlines two important aspects of the effects of carbogen. (1) Carbogen can increase elimination of 5FU from the plasma, presumably through effects on other tissues besides the tumour; and the intensity of this effect may be related to the length of time of carbogen breathing. (2) Carbogen can increase drug exchange between blood and tumour, although without a secondary mechanism to trap the drug in the tumour, e.g. an increase of $V_{2}$ by partitioning or stimulation of $\mathrm{CL}_{\mathrm{m}}$, there will be no net increased retention of drug. The previous study with RIF-1 tumours showed that $5 \mathrm{FU}$ was only significantly retained in large tumours of $2-3 \mathrm{~g}$, but not smaller tumours of $0.8-1.6 \mathrm{~g}$ [19]. The large tumours were also characterised by (i) increased retention of a hypoxic marker compared to the smaller tumours and (ii) a carbogen-induced decrease in $\mathrm{pH}_{\mathrm{e}}$ causing an increase in the mean negative $\mathrm{pH}$ gradient $(-\Delta \mathrm{pH})$. Uptake of $5 \mathrm{FU}$ by isolated tumour cells has been shown to be proportional to the magnitude of the $\Delta \mathrm{pH}$ across the cell plasma membrane [22] and experiments in vivo have demonstrated that increases in the $-\Delta \mathrm{pH}$ are associated with increased retention of $5 \mathrm{FU}$, specifically an increase in the $t_{1 / 2}$ for $5 \mathrm{FU}$ elimination [20]. Changes in the $\mathrm{pH}_{\mathrm{e}}$ of $\mathrm{GH} 3$ xenografts in response to carbogen were not monitored in this study, but there was clearly no change in the tumour energy status (NTP/Pi). However, in H9168a, small but consistent increases in both the $-\Delta \mathrm{pH}$ (via a decrease in $\mathrm{pH}_{\mathrm{e}}$ ) and NTP/Pi ratio could be detected. Such effects might promote both 5FU uptake and metabolism to FNuct, since the latter is certainly an ATP-dependent process. Indeed, carbogen had no effect on the FNuct/ 5FU ratio in GH3 tumours, but significantly increased this ratio in H9168a tumours. However, unlike in RIF-1 tumours, the $\mathrm{pH}$ and energy effects of carbogen were rapidly reversible, perhaps explaining the lack of any major effect on overall retention of drug and/or metabolites by these tumours.

A study using chemically induced primary rat mammary tumours demonstrated that initial tumour NTP/Pi levels were positively and significantly correlated with response to $5 \mathrm{FU}$ [16]. A similar relationship was described in RIF-1 tumours [35]. This relationship may indicate that 5FU readily gains access to wellperfused tumours, but also that ATP levels can be ratelimiting in activation of 5FU to FNuct. Therefore, any 
treatment that leads to an increase in the NTP/Pi, such as increased oxygenation or glucose supply, may aid tumour sensitivity to $5 \mathrm{FU}$, and the corollary is that hypoxic regions of tumour would be less sensitive to 5FU. We have shown that carbogen breathing increases the GRE-image intensity, which would be consistent with an increase in tumour blood flow, and thus increased amounts 5FU would be available for extraction by the tissue. Furthermore, carbogen breathing has been shown to cause an increase in blood glucose from liver glycogen breakdown [37], an increase in tissue $\mathrm{pO}_{2}$ [30] and a decrease in $\mathrm{pH}_{\mathrm{e}}$ [ref. 19 and this paper]. Thus, in the case of 5FU, carbogen could be a principle act on three different loci within the tumour to increase drug uptake and activation: (i) increased blood flow across the tumour; (ii) a more acidic $\mathrm{pH}_{\mathrm{e}}$ with a larger $-\Delta \mathrm{pH}$; and (iii) an increase in the NTP/Pi ratio enhancing FNuct formation. Unfortunately, in the case of the H9168a hepatoma, where all these effects were demonstrated to occur, (ii) and (iii) proved too readily reversible, and (i) persisted, which ultimately allowed greater drug elimination so that there was little or no improvement in drug retention and activation. In short, these studies suggest that only in tumours that are hypoxic, as defined by significant retention of nitroimidazoles and/or a low $\mathrm{NTP} / \mathrm{Pi}$ ratio, may carbogen provide clinical benefit by increasing 5 FU uptake and retention. This could be tested in a well-defined hypoxic tumour model such as murine EMT6 to investigate if hypoxia is the key to carbogeninduced increases in drug retention.

\section{References}

1. Al-Hallaq HA, River JN, Zamora M, Oikawa H, Karczmar GS (1998) Correlation of magnetic resonance and oxygen microelectrode measurements of carbogen-induced changes in tumor oxygenation. Int J Radiat Oncol Biol Phys 41:151-159

2. Anderson BJ, McKee AD, Holford NHG (1997) Size, myths and the clinical pharmacokinetics of analgesia in paediatric patients. Clin Pharmacokinet 33:313-327

3. Beal SL, Sheiner LB (eds) (1992) NONMEM user's guides. NONMEM project group. University of California, San Francisco

4. Benet LZ (1972) General treatment of linear mammillary models with elimination from any compartment as used in pharmacokinetics. J Pharm Sci 61:536-541

5. Brown JM, Giaccia AJ (1998) The unique physiology of solid tumors: opportunities (and problems) for cancer therapy. Cancer Res 58:1408-1416

6. Dunn TJ, Braun RD, Rhemus WE, Rosner GL, Secomb TW, Tozer GM, Chaplin DJ, Dewhirst MW (1999) The effects of hyperoxic and hypercarbic gases on tumour blood flow. Br J Cancer 80:117-126

7. Griffiths JR, Taylor NJ, Howen FA, Saunders MI, Robinson SP, Hoskin PJ, Powell MEB, Thoumine M, Caine LA, Baddeley H (1997) The response of human tumors to carbogen breathing, monitored by gradient-recalled echo magnetic resonance imaging. Int J Radiat Oncol Biol Phys 39:697-701

8. Helmer KG, Han S, Sotak CH (1998) On the correlation between the water diffusion coefficient and oxygen tension in RIF-1 tumors. NMR Biomed 11:120-130
9. Hill SR, Bibby MC (1994) 5-Fluorouracil causes alterations in the pharmacokinetic profile of tauromustine in NMRI mice. Cancer Chemother Pharmacol 34:57-62

10. Howe FA, Robinson SP, Rodrigues LM, Griffiths JR (1999) Flow and oxygenation dependent (FLOOD) contrast MR imaging to monitor the response of rat tumors to carbogen breathing. Magn Reson Imaging 17:1307-1318

11. Howe FA, Robinson SP, McIntyre DJO, Stubbs M, Griffiths JR (2001) Issues in flow oxygenation dependent contrast (FLOOD) imaging of tumours. NMR Biomed 14:497-506

12. Ilangovan $\mathrm{G}, \mathrm{Li} \mathrm{H}$, Zweier JL, Krishna MC, Mitchell JB, Kuppusamy $P$ (2002) In vivo measurement of regional oxygenation and imaging of redox status in RIF-1 murine tumor: effect of carbogen-breathing. Magn Reson Med 48:723730

13. Kamm YJ, Heerschap A, Wagener DJ (2000) Effect of carbogen breathing on the pharmacodynamics of 5-fluorouracil in a murine colon carcinoma. Eur J Cancer 36:1180-1186

14. Kamm YJ, Peters GJ, Hull WE, Punt CJ, Heerschap A (2003) Correlation between 5-fluorouracil metabolism and treatment response in two variants of $\mathrm{C} 26$ murine colon carcinoma. Br J Cancer 89:754-762

15. Lansen JL, Braun RD, Ong AL, Dewhirst MW (1998) Variability in blood flow and $\mathrm{pO}_{2}$ in tumors in response to carbogen breathing. Int J Radiat Oncol Biol Phys 42:855-859

16. Lemaire LP, McSheehy PMJ, Griffiths JR (1998) Pre-treatment energy status of primary rat tumours as the best predictor of response to 5-fluorouracil chemotherapy: a magnetic resonance spectroscopy study in vivo. Cancer Chemother Pharmacol 42:201-209

17. McSheehy PMJ, Prior MJW, Griffiths JR (1989) Prediction of 5-fluorouracil cytotoxicity towards the Walker carcinosarcoma using peak integrals of fluoronucleotides measured by MRS in vivo. Br J Cancer 60:303-309

18. McSheehy PMJ, Seymour MT, Ojugo AS, Rodrigues LM, Leach MO, Judson IR, Griffiths JR (1997) A pharmacokinetic and pharmacodynamic study in vivo of human HT29 tumours using $19 \mathrm{~F}$ and $31 \mathrm{P}$ magnetic resonance spectroscopy. Eur $\mathbf{J}$ Cancer 33:2418-2427

19. McSheehy PMJ, Robinson SP, Ojugo ASE, Cannell MB, Leach MO, Judson IR, Griffiths JR (1998) Carbogen breathing increases 5-fluorouracil uptake and cytotoxicity in hypoxic murine RIF-1 tumours: a magnetic resonance study in vivo. Cancer Res 58:1185-1194

20. McSheehy PMJ, Stubbs M, Griffiths JR (2000) Role of pH in tumour-trapping of the anticancer drug 5-fluorouracil. Adv Enzyme Regul 40:63-80

21. Nakashima E, Benet LZ (1989) An integrated approach to pharmacokinetic analysis for linear mammillary systems in which input and exit may occur in/from any compartment. J Pharmacokin Biopharm 17:673-686

22. Ojugo ASE, McSheehy PMJ, Stubbs M, Alder G, Maxwell R, Bashford CL, Leach MO, Judson IR, Griffiths JR (1998) Influence of $\mathrm{pH}$ on the uptake of 5-fluorouracil into isolated tumour cells. Br J Cancer 77:873-879

23. Ojugo ASE, McSheehy PMJ, McIntyre DJO, McCoy C, Stubbs M, Leach MO, Judson IR, Griffiths JR (1999) Measurement of the extracellular $\mathrm{pH}$ of solid tumours in mice by magnetic resonance spectroscopy: a comparison of exogenous ${ }^{19} \mathrm{~F}$ and ${ }^{31} \mathrm{P}$ probes. NMR Biomed 12:495504

24. Peters GJ, Lankelma J, Kok RM, Noordhuis P, van Groeningen CJ, van der Wilt CL, Meyer S, Pinedo HM (1993) Prolonged retention of high concentrations of 5-fluorouracil in human and murine tumours as compared with plasma. Cancer Chemother Pharmacol 31:269-276

25. Port RE, Hanisch F, Becker M, Bachert P, Zeller WJ (1999) Local disposition kinetics of floxuridine after intratumoral and subcutaneous injection, monitored by $19 \mathrm{~F}$ nuclear magnetic resonance (MRS) spectroscopy in vivo. Cancer Chemother Pharmacol 44:65-73 
26. Presant CA, Wolf W, Waluch V, Wiseman C, Kennedy P, Blayney D, Brechner RR (1994) Association of intratumoral pharmacokinetics of fluorouracil with clinical response. Lancet 343:1184-1187

27. Robinson SP, Howe FA, Griffiths JR (1995) Noninvasive monitoring of carbogen-induced changes in tumour blood flow and oxygenation by functional magnetic resonance imaging. Int J Radiat Oncol Biol Phys 33:855-859

28. Robinson SP, Rodrigues LM, Ojugo ASE, McSheehy PMJ, Howe FA, Griffiths JR (1997) The response to carbogen breathing in experimental tumour models monitored by gradient-recalled echo magnetic resonance imaging. Br J Cancer 75:1000-1006

29. Robinson SP, Howe FAH, Rodrigues LM, Stubbs M, Griffiths JR (1998) Magnetic resonance imaging techniques for monitoring changes in tumor oxygenation and blood flow. Semin Radiat Oncol 8:197-207

30. Robinson SP, Howe FA, Stubbs M, Griffiths JR (2000) Effects of nicotinamide and carbogen on tumour oxygenation blood flow, energetics and blood glucose levels. Br J Cancer 82:20072014

31. Rodrigues LM, Maxwell RJ, McSheehy PMJ, Pinkerton CR, Robinson SP, Stubbs M, Griffiths JR (1997) In vivo detection of ifosfamide by ${ }^{31} \mathrm{P}$-MRS in rat tumours: increased uptake and cytotoxicity induced by carbogen breathing in $\mathrm{GH} 3$ prolactinomas. Br J Cancer 75:62-68

32. Rodrigues LM, Robinson SP, McSheehy PMJ, Stubbs M, Griffiths JR (2002) Enhanced uptake of ifosfamide into GH3 prolactinomas with hypercapnic hyperoxic gases monitored in vivo by ${ }^{31} \mathrm{P}$ MRS. Neoplasia 4:539-543
33. Rojas A (1991) Radiosensitization with normobaric oxygen and carbogen. Radiother Oncol 20(Suppl 1):65-70

34. Sheiner LB, Ludden TM (1992) Population pharmacokinetics/ dynamics. Annu Rev Pharmacol Toxicol 32:185-209

35. Sijens PE, Huang Y, Baldwin NJ, Ng TC (1991) ${ }^{19}$ F magnetic resonance spectroscopy studies of the metabolism of 5-fluorouracil in murine RIF-1 tumours and liver. Cancer Res 51:1384 1390

36. Stubbs M, Rodrigues LM, Griffiths JR (1989) Potential artefacts from overlying tissues in ${ }^{31} \mathrm{P}$ NMR spectra of subcutaneously implanted rat tumours. NMR Biomed 1:165-170

37. Stubbs M, Robinson SP, Rodrigues LM, Parkins CS, Collingridge DR, Griffiths JR (1998) The effects of host carbogen (95\% oxygen $/ 5 \%$ carbon dioxide) breathing on metabolic characteristics of Morris hepatoma 9618a. $\mathrm{Br} \mathrm{J}$ Cancer 78:1449-1456

38. Taylor NJ, Baddeley H, Goodchild KA, Powell MEB, Thoumine M, Culver LA, Stirling JJ, Saunders MI, Hoskin PJ, Phillips H, Griffiths JR (2001) BOLD MR imaging of human tumour oxygenation during carbogen breathing. Magn Reson Imaging 14:156-163

39. Van der Sanden BPJ, Heerschap A, Hoofd L, Simonetti AW, Nicolay K, van der Toorn A, Colier WNJM, van der Kogel AJ (1999) Effect of carbogen breathing on the physiological profile of human glioma xenografts. Magn Reson Med 42:490-499

40. West GB, Brown JH, Enquist BJ (1997) A general model for the origin of allometric scaling laws in biology. Science 276:122-126 